\title{
COEXISTENCIA DE LENGUAS Y PLANIFICACIÓN LINGÜÍSTICA: LA CONVIVENCIA DEL CASTELLANO Y CATALÁN EN CATALUÑA
}

\author{
LUIS ESCORIZA MORERA \\ Universidad de Cádiz \\ luis.escoriza@uca.es
}

\begin{abstract}
Resumen
En el marco de una denominada planificación lingüística de determinación, en la que se intenta solventar situaciones problemáticas derivadas de la presencia de varios sistemas lingüísticos en contacto, existen en el panorama internacional diferentes modelos que permiten establecer una tipología de actuaciones encaminadas a regular el uso y la coexistencia de dichas modalidades en un mismo espacio geográfico. Dichas actuaciones se reflejan en el establecimiento de diferentes modelos educativos y en el control de los medios de comunicación. En el desarrollo histórico de la planificación lingüística en Cataluña en el último siglo podemos observar cómo la defensa del unilingüismo hispanófono ha dado paso a la aparición de un marco legal dirigido al fomento de la lengua catalana. Por tanto, el objetivo de este trabajo es el de recoger las cuestiones inherentes al controvertido marco actual de decisiones, incluyendo tanto los argumentos que lo sostienen como los movimientos de reacción frente al mismo.
\end{abstract}

PALABRAS CLAVE: política lingüística, bilingüismo, planificación lingüística, conflicto lingüístico.

\begin{abstract}
In the framework of language policy and planning there are various regulations intended to establish the use of different linguistic varieties within the same geographical area. Said regulations, which generally oscillate from monolingual to multilingual approaches, can be seen mainly in the fields of education, the media and the public administration. In Catalonian history there has been a change from centralized Castillian linguistic policies to the establishment of regulations for the promotion of the Catalan language. This paper is aimed at analyzing the existing points of view with regard to the use of Spanish and Catalan in Catalonia, stressing the legal framework that justifies them, as well as their underlying objectives and possible consequences.
\end{abstract}

KEYWORDS: linguistic politic, bilingualism, linguistic planning, linguistic conflict.

\section{Multilingüismo y política lingüística}

La diversidad lingüística, la existencia de distintos sistemas lingüísticos que responden a un mismo fenómeno, el lenguaje humano, principal sistema de comunicación de la especie, proporciona numerosas opciones de investigación en el marco de una Lingüística 
general que, precisamente, concibe la capacidad lingüística y sus diferentes formalizaciones como su principal objeto de estudio.

El mapa de lenguas del mundo que configura la diversidad actual solo puede comprenderse como el producto de un progresivo proceso histórico de fragmentación. Las lenguas, basadas en un mismo principio de arbitrariedad y vinculadas al carácter humano, cambian y los pueblos que las hablan se han separado históricamente y aún hoy se separan, otorgando a los diferentes cambios lingüísticos adoptados a partir de lo que era una misma lengua un carácter identitario de suma importancia. En este sentido, puede resultar sencillo entender, por ejemplo, que las lenguas española, francesa, italiana o catalana son sistemas herederos de una misma lengua, el latín, pero si seguimos retrocediendo en el proceso histórico de fragmentación lingüística puede ser más complicado identificar a hablantes actuales de alemán, español, ruso o hindi, por citar algunos, como descendientes de un único pueblo indoeuropeo hablante de una lengua indoeuropea de la que han surgido las citadas.

El carácter errático de la separación de pueblos y la naturaleza lenta y progresiva del proceso de cambio lingüístico podría invitar a pensar en el establecimiento por parte de la Lingǘstica de criterios claros y precisos para delimitar el momento en el que una forma de hablar se ha convertido en una lengua diferente a aquella de la que proviene o a aquellas con las que coexiste, es decir, qué cambios lingüísticos deben darse en una modalidad lingüística de un grupo de hablantes para que dicha modalidad sea considerada una lengua diferente. Por poner un ejemplo, cuánto tuvo que cambiar el latín para dejar de ser latín y convertirse en español, francés, italiano o catalán.

Sin embargo, los conceptos englobados bajo los términos lingüísticos usados para identificar las distintas formas de hablar en el mundo (lengua, dialecto, habla regional, habla local, etc.) no se fundamentan en el grado de especificidad o diferenciación lingüística. Es curioso que puedan encontrarse más diferencias lingüísticas, por ejemplo, entre algunos dialectos del norte de Europa y aquellas lenguas con respecto a las que se consideran dialectos que entre lenguas consideradas diferentes, como algunas de las lenguas románicas mencionadas con anterioridad.

En la delimitación de modalidades lingüísticas, en la adscripción de los diferentes términos usados para designar las diferentes formas de hablar surgidas progresivamente de ese constante proceso de fragmentación, cobran vital importancia otros factores, lingüísticos o no, que tienen tanta incidencia como el grado de diferenciación lingüística de cada modalidad. En realidad podemos diferenciar aspectos filológicos de otros criterios de naturaleza claramente extralingüística. Entre los primeros podemos incluir el grado de diferenciación lingüística, asociado al grado de inteligibilidad o intercomprensión; el grado de nivelación, es decir, la existencia o no de un modelo normativo de referencia, y la existencia de mayor o menor tradición literaria. Más allá del ámbito lingüístico debemos citar la extensión geográfica de la modalidad lingüística y su coincidencia o no con límites de naturaleza política; la existencia de factores históricos, sociales y políticos vinculados al conjunto de hablantes que domina la modalidad, y el grado de identidad de dicho grupo de 
hablantes y la conciencia de sus diferencias idiomáticas como conformadoras de esa identidad.

\begin{tabular}{|l|c|c|c|}
\hline \multicolumn{4}{|c|}{ Criterios de delimitación de modalidades lingüísticas } \\
\hline Filológicos & $\begin{array}{c}\text { Rasgos lingüísticos } \\
\text { diferenciales }\end{array}$ & Grado de nivelación & Tradición literaria \\
\hline Extralingüísticos & Extensión geográfica & Factores históricos & Grado de identidad \\
\hline
\end{tabular}

Tabla 1: Criterios de delimitación de modalidades lingüísticas

Fuente: Elaboración propia

Entre los diferentes campos de investigación integrados en la política y planificación lingüisticas, entendida como disciplina o subdisciplina lingüística de naturaleza sociolingüística dedicada al estudio de toda medida de carácter institucional que pretenda y/o pueda ejercer influencia sobre el uso de las lenguas, es, precisamente, la gestión de la coexistencia de modalidades lingüísticas en un mismo espacio geográfico el que ha suscitado más interés y ha generado más bibliografía hasta la fecha, debido, fundamentalmente, a la presencia de numerosos casos objeto de estudio derivados de la existencia de varios miles de modos de hablar en un mundo, como el actual, con muchas menos divisiones territoriales de naturaleza política que sistemas lingüísticos. Se han descrito diferentes modelos de actuación denominados por diversos autores (cf. por ejemplo F. Moreno Fernández 2005: 332) modelos de determinación lingüística, destinados a regular el uso de diferentes lenguas en ámbitos de dominio público.

\section{La diversidad de lenguas en Cataluña}

En España son varias las lenguas ${ }^{1}$ que han coexistido y/o coexisten en la actualidad. La vigencia hoy de catalán, gallego y vasco, junto al castellano o español ${ }^{2}$, las singulariza de

\footnotetext{
${ }^{1}$ En consonancia con lo expuesto anteriormente, podríamos hablar en España de la existencia de diferentes modalidades lingüísticas sean consideradas lenguas, dialectos, hablas regionales o hablas locales. Como quiera que dicha diferenciación puede presentar diferentes interpretaciones y que en ella, como hemos intentado mostrar, entran en juego criterios no solo de naturaleza lingüística sino también consideraciones de carácter extralingüístico, la nómina de las consideradas lenguas que se hablan en España podría variar en función del autor o incluso el organismo oficial que las considere. En cualquier caso dicho aspecto no afecta de manera general a la consideración de catalán y castellano, objeto de estudio de este trabajo, como lenguas habladas en España.

${ }^{2}$ La diferente denominación de la lengua más hablada en el Estado español es, o puede ser, un tema controvertido. Castellano y español son denominaciones que han sido usadas de manera paralela para designar a esa lengua durante varios siglos. La redacción de la Constitución española en 1978 ya reveló con claridad la posible existencia de connotaciones en cada uno de los términos (cf. Montero Cartelle 1979). Actualmente son diversas las posturas documentadas bibliográficamente, desde aquella representada por los autores que prefieren usar castellano porque consideran, fundamentalmente, que todas las lenguas
} 
manera clara frente a otras modalidades lingüísticas. Y entre ellas parece claro que el catalán, objeto por ello de esta investigación, ofrece unas particularidades que hacen su estudio aún más interesante, ya que dicha lengua se encuentra en su Comunidad Autónoma en la mejor situación tanto desde el punto de vista lingüístico como político. En lo que respecta a la dimensión lingüística podemos citar como ventajas el alto nivel de competencia lingüística de los habitantes de la comunidad, el prestigio social de la lengua o la poca distancia lingüística entre las lenguas catalana y española, factores que no se dan de la misma manera y con la misma fuerza en otras lenguas del Estado español. Además, desde el punto de vista político, cabe destacar la existencia de partidos políticos que defienden abiertamente la lengua propia de la Comunidad y el elevado número de escaños obtenidos por esos partidos en comparación con otras fuerzas políticas más cercanas al nacionalismo españolista y probablemente más reticentes a determinadas medidas (que veremos más adelante) relacionadas con la normalización lingüística de la lengua propia de la Comunidad (cf. Subirats i Humet y Gomá 1998: 300-301).

Nuestro objetivo es describir de manera somera el desarrollo de la convivencia de las lenguas castellana y catalana, haciendo mención no solo a su uso en la Comunidad Autónoma catalana sino a las diferentes medidas legislativas que han podido servir de apoyo a la hora de adoptar diferentes medidas sobre las mismas. Ese interesante y en gran medida ambiguo marco legal explica actuaciones de muy distinto signo encaminadas a la defensa y promoción de ambas lenguas y ha propiciado lo que podríamos definir como un auténtico conflicto lingüístico. Intentaremos recoger aquí algunos de los argumentos más destacados en ese debate, mostrar las medidas más ilustradoras de dichos argumentos $\mathrm{y}$, finalmente, reflexionar acerca de las posibilidades reales de futuro de la situación lingüística en Cataluña.

\section{Breve panorama histórico y jurídico}

Las lenguas castellana y catalana son ambas lenguas indoeuropeas pertenecientes a la subfamilia de las lenguas romances herederas del latín. La extensión de la lengua del Imperio romano por diferentes territorios dio origen con el paso del tiempo y la caída de dicho Imperio a distintas lenguas que son producto del latín vulgar, lenguas diferenciadas en parte por el sustrato lingüístico de las lenguas preexistentes a la imposición del latín y a

\footnotetext{
habladas en España son españolas y ninguna debe denominarse español hasta la defendida por quienes abogan por el uso de español por considerar esta lengua como la única lengua común en España y evitan así la posible ambigüedad del término castellano que podría designar también tanto al primitivo dialecto histórico nacido en el siglo XI como a la modalidad dialectal actual de la lengua común en zona castellana, pasando por otros planteamientos intermedios de quienes defienden el carácter sinonímico de ambas denominaciones, postulan el uso de una tercera formulación para evitar controversias o recomiendan una especialización funcional de ambos términos reservando castellano cuando se habla de esta lengua junto a otras lenguas de España y español cuando nos referimos a la misma en un contexto internacional (puede verse un desarrollo de la cuestión más desarrollado en Escoriza Morera 2008: 33-39).
} 
las progresivas diferencias adoptadas por los hablantes en cada zona donde el latín se hablaba.

En la diferente evolución del latín hacia lo que serán más tarde las diferentes lenguas románicas ${ }^{3}$ el castellano y el catalán se constituyen desde el siglo XI como modalidades lingüísticas asociadas, respectivamente, a los reinos de Castilla y Aragón, con una distribución geográfica relativamente clara y diferenciada, una vitalidad indiscutible y una rica expresión literaria. El proceso de unificación iniciado en el siglo XV conlleva una mayor penetración del castellano en la península. Dicho castellano, que empieza ya a ser denominado también español (cf. nota 2) y alcanza su máximo esplendor literario, se convierte en la modalidad lingüística predominante ${ }^{4}$, lo que no impide, ni mucho menos, la pervivencia de otras lenguas como el catalán. Esa situación se extiende durante siglos y llega hasta nuestros días. Merece la pena destacar la destacada recuperación lingüística y literaria del catalán a fines del siglo XIX y comienzos del XX en la denominada Renaixença. En el siglo XX se producen acontecimientos históricos importantes para comprender la repercusión de la Historia en la situación actual. Por una parte, es evidente que en el período de dictadura franquista todas las lenguas diferentes a la lengua común no gozaron de ningún tipo de apoyo o protección oficial, quedando relegadas al uso familiar, fuera del alcance del control institucional. Por el contrario, el proceso de democratización en España a partir, fundamentalmente, de la redacción de la Constitución de 1978, va a dar lugar a diferentes documentos oficiales, en los que nos detendremos más detenidamente más adelante, que recogen y avalan medidas de fomento y cuidado de las distintas lenguas habladas en el país.

No podemos conocer con exactitud la situación real de la convivencia de ambas lenguas desde un punto de vista sociolingüístico durante todo el proceso histórico transcurrido desde su aparición hasta la actualidad, pero en las últimas décadas sí ha habido intentos más sólidos por describir el nivel de competencia de la población residente en Cataluña en ambas lenguas. En este sentido, en el año 2008 la Generalitat de Cataluña publicó los resultados de la encuesta de carácter global más reciente sobre usos lingüísticos de la población catalana. En ella puede apreciarse que el nivel de conocimiento de ambas lenguas es bastante alto, aunque el predominio del castellano es general.

\footnotetext{
${ }^{3}$ Junto a las lenguas que centran el objeto de este trabajo hay otras lenguas derivadas de la lengua latina como el francés, el italiano, el rumano, el portugués, el gallego, el sardo, el retorromance o el occitano.

${ }^{4}$ Existen diferentes puntos de vista acerca de la extensión de la lengua castellana a través de los siglos, desde planteamientos, quizás los más comunes, que consideran que existió una imposición lingüística derivada del poder político hasta aquellos otros que postulan que el castellano fue aceptado de manera más natural como consecuencia directa de la importancia y prestigio del reino que lo tenía como su lengua (cf. en este sentido J. R. Lodares 2000).
} 


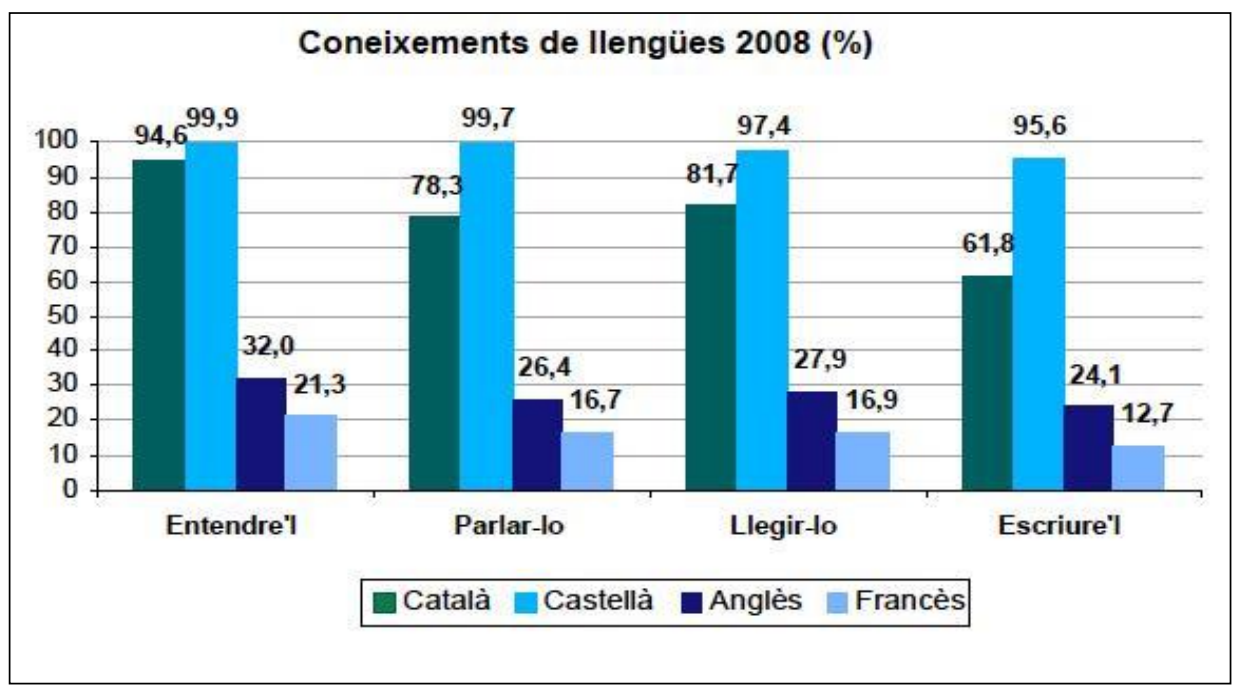

Figura 1: Conocimiento de lenguas por destrezas en Cataluña

Fuente: Generalitat de Cataluña

El reconocimiento histórico de los derechos, tanto individuales como colectivos, relacionados con el uso de una lengua en situaciones multilingües no ha tenido un desarrollo similar al de otros derechos claramente reconocidos en textos legales de referencia internacional (cf. Hamel 1995) como la Carta de las Naciones Unidas, la Declaración Universal de los Derechos Humanos o la Convención Internacional de los Derechos Civiles y Políticos 5 . Con respecto al marco jurídico que especifica el tratamiento de las lenguas en España en las últimas décadas hay que mencionar la Constitución de 1978 como marco de referencia general; otras disposiciones generales como los diferentes estatutos de autonomía u otras leyes generales y específicas sobre política lingüística, y diferentes textos legislativos y recursos al Tribunal constitucional sobre aspectos más concretos relacionados con el uso oficial de las lenguas.

La Constitución vigente recoge, en el artículo tercero de su título preliminar, las siguientes consideraciones de índole lingüística:

«1. El castellano es la lengua española oficial del Estado. Todos los españoles tienen el deber de conocerla y el derecho a usarla.

2. Las demás lenguas españolas serán también oficiales en las respectivas Comunidades Autónomas de acuerdo con sus Estatutos.

\footnotetext{
${ }^{5}$ No debemos olvidar que existe una Declaración Universal de Derechos Lingüísticos firmada en Barcelona en 1998, texto redactado por diferentes entidades no gubernamentales y apoyada por UNESCO, que, no obstante, no ha conseguido constituirse en referente legal en materia de gestión del multilingüismo.
} 
3. La riqueza de las distintas modalidades lingüísticas de España es un patrimonio cultural que será objeto de especial respeto y protección.» (Constitución española: 29315).

Dicha formulación justifica las acciones de protección de la lengua catalana pero no especifica con claridad cuál debe ser el alcance de las mismas ni la manera correcta de interpretar la coexistencia de castellano y catalán en el uso público al tiempo que otorga la gestión de la cooficialidad a otras disposiciones generales autonómicas como los Estatutos. En este sentido, en Cataluña se han redactado diferentes textos que sirven de referencia para la planificación lingüística que sobre el catalán se ha llevado a cabo en las últimas décadas, fundamentalmente el Estatuto de Autonomía y la Ley 1/1998, de 7 de enero, de política lingüística. La controversia generada por diferentes medidas de la planificación lingüística sobre el catalán en Cataluña viene dada precisamente, entre otras cosas, por la indefinición de la Carta Magna en esta cuestión (que hace que puedan interpretarse como inconstitucionales determinadas medidas) así como por cierta ambigüedad derivada de la redacción de las mencionadas disposiciones autonómicas, que analizaremos más adelante.

De manera general, como adelanto a nuestro posterior análisis, podemos sintetizar la citada ambigüedad en dos afirmaciones presentes en varios de los textos legales mencionados: por una parte, se considera al catalán como lengua propia de Cataluña, lo que implica que su uso es el normal y preferente en todos los contextos de regulación oficial de las lenguas, esto es, en las Administraciones públicas, en los medios de comunicación y en la enseñanza; por otra parte, se reconoce que tanto el catalán como el castellano son lenguas oficiales $y$, por tanto, cualquier ciudadano tiene el derecho a utilizar ambas lenguas y no puede haber discriminación por el uso de cualquiera de ellas ${ }^{6}$.

\section{La defensa y la promoción de la lengua catalana}

En consonancia con lo expresado anteriormente y basándose en las posibilidades de ese marco legal las autoridades políticas catalanas han establecido diferentes medidas destinadas a la defensa y el fomento del catalán. En este sentido, cabe mencionar la existencia de un amplio organigrama que muestra la organización del gobierno en materia de política lingüística, de manera similar a lo que ocurre en otros países?

La Dirección General de Política Lingüística, adscrita al Departamento de Cultura de la Generalitat de Cataluña, gestiona diferentes servicios como el servicio de fomento del uso

\footnotetext{
${ }^{6}$ Sobre las distintas denominaciones utilizadas en política lingüística para designar a las lenguas y sus posibles implicaciones legales cf. Ruíz Vieytez (2004) o Süselbeck (2008).

${ }^{7}$ La estructura oficial dedicada a aspectos de planificación lingüística en Francia es, por ejemplo, habitualmente citada como modelo de referencia de las posibilidades de desarrollo gubernamental en la promoción de la lengua, en este caso el francés. La dedicación en este sentido del estado español con respecto a la gestión de la lengua española presenta cierta controversia ya que, a pesar de la existencia de organismos especializados en la promoción del español como el Instituto Cervantes, podría cuestionarse si la dimensión de esa dedicación es la más adecuada.
} 
del catalán; el servicio de recursos lingüísticos; el servicio de información, difusión y estudios (dentro del cual se contempla un centro de documentación), y la sección de actuación administrativa. Además, son numerosos los organismos que, dependiendo directamente de dicha Dirección General o no, participan en la política lingüística del gobierno. Entre estos podemos mencionar la Comisión Técnica de política lingüística, el Centro de Terminología (TERMCAT), la Comisión de toponimia, el Consorcio para la Normalización lingüística, el Consejo Social de la Lengua Catalana o diferentes organizaciones dedicadas a la promoción de la lengua y cultura catalanas específica o parcialmente como el Instituto Ramon Llul, el Instituto de Estudios Catalanes o la Casa de las lenguas (Linguamón).

La política lingüística hacia el catalán se manifiesta fundamentalmente, como toda política lingüística, en los tres ámbitos ya citados que recogen de manera general la regulación pública del uso de las lenguas: la educación, los medios de comunicación y la Administración. Para cada uno de esos ámbitos existen artículos concretos en la ley de política lingüística de enero de 1998 anteriormente mencionada que respaldan actuaciones de fomento del catalán.

En lo que respecta a la educación, el capítulo III de la citada ley se dedica íntegramente a la enseñanza $y$, si bien recoge que «los niños tienen derecho a recibir la primera enseñanza en su lengua habitual, ya sea ésta el catalán o el castellano» y que «la enseñanza del catalán y del castellano debe tener garantizada una presencia adecuada en los planes de estudio» (Ley 1/1998: 305), el primer artículo del citado capítulo recoge que «el catalán, como lengua propia de Cataluña, lo es también de la enseñanza, en todos los niveles y modalidades educativos» y que «los centros de enseñanza de cualquier nivel deben hacer del catalán el vehículo de expresión normal en sus actividades docentes y administrativas, tanto internas como externas» (op. cit.: 304). Hablamos de un marco legal, como puede observarse, lo suficientemente ambiguo como para recoger diferentes tipos de modelos educativos en materia de lengua, en función de la voluntad política de los diferentes agentes implicados en la gestión de la enseñanza y que, por tanto, también sirve para desarrollar en algunos casos una política educativa muy favorable al desarrollo de la lengua catalana.

Algo similar ocurre en los otros dos ámbitos mencionados. En el capítulo IV, dedicado a los medios de comunicación y las industrias culturales, se especifica que «la lengua normalmente utilizada debe ser la catalana» (op.cit.: 307), al tiempo que se establecen cuotas mínimas de uso de dicha lengua en medios de radiodifusión y televisión y se recoge el fomento y la subvención de tales medidas. En lo que respecta a la Administración pública, ya el capítulo I de la ley, dedicado al uso institucional, recoge que «la Generalitat, las administraciones locales y las demás corporaciones públicas de Cataluña, las instituciones y empresas que dependen de las mismas y los concesionarios de sus servicios deben utilizar el catalán en sus actuaciones internas y en la relación entre ellos» (op.cit.: 299). También aparecen en el texto que estamos comentando diferentes menciones a aspectos concretos relacionados con el uso público del catalán como la onomástica o la atención al público, por citar algunos. En el primer caso se señala que «los topónimos de 
Cataluña tienen como única forma oficial la catalana» (op.cit.: 303) y en el segundo, a pesar de que la ley contempla la necesidad de que la atención al público pueda efectuarse en las dos lenguas oficiales, se recoge que la Generalitat fomentará el incremento del uso del catalán y que, por ejemplo, «la señalización y los carteles de información general de carácter fijo y los documentos de oferta de servicios para las personas usuarias y consumidoras de los establecimientos abiertos al público deben estar redactados, al menos, en catalán» (op.cit.: 311).

Podemos afirmar, pues, que en Cataluña, pese a que existen diferentes comportamientos en el tratamiento del uso de las dos lenguas oficiales, en las últimas décadas ha habido, sin lugar a dudas y merced en parte al desarrollo del marco legal comentado, un notable incremento de actuaciones llevadas a cabo por el gobierno catalán para el fomento de la lengua catalana.

\section{Los movimientos de reacción castellanista}

Como contrapartida al aumento de la planificación lingüística hacia el catalán debemos mencionar la existencia también en los últimos años de voces que reclaman un tratamiento similar hacia el castellano por parte del Estado español, llegándose a denunciar en algunos casos discriminación en razón del uso de la lengua ${ }^{8}$.

Además de diferentes acciones de protesta, desarrolladas en muchas ocasiones en el ámbito judicial, varias personalidades han mostrado su preocupación por una política lingüística que, más allá de promocionar el bilingüismo, podría perjudicar a la lengua castellana. Un ejemplo que ilustra de manera clara las reivindicaciones más habituales en este sentido es el denominado «Manifiesto por la lengua común», presentado en junio de 2008 en el Ateneo de Madrid por un grupo de intelectuales de distintos ámbitos profesionales y al que, progresivamente, fueron manifestando su adhesión diferentes personas e instituciones, entre estas, por ejemplo, el Partido Popular, que dos días después de su aparición expresaba públicamente su apoyo al texto. Dicho texto, que alude a la gestión del multilingüismo en todo el Estado español, se articula en torno a cuatro premisas generales, que reflejan ideas repetidas en las voces más críticas con las políticas de fomento de la lengua catalana y pueden resumirse del siguiente modo:

-solo hay una lengua española común a toda la nación y debe ser, por ello, la única cuyo conocimiento puede ser exigido a los ciudadanos españoles;

-los derechos lingüísticos deben ser individuales (de los ciudadanos) y no colectivos (de los territorios);

-el conocimiento de las lenguas cooficiales distintas a la lengua común no puede ser impuesto, solo estimulado, $y$

-no puede existir discriminación lingüística hacia hablantes monolingües castellanos.

\footnotetext{
${ }^{8}$ Un ejemplo significativo y polémico, por el debate acerca de su objetividad, es el documental emitido por la cadena televisiva Telemadrid en 2007 con el título «Ciudadanos de segunda».
} 
Junto a dichas premisas el manifiesto solicita que el Parlamento español elabore una normativa legal que recoja diferentes reivindicaciones como las siguientes:

-el castellano es la única lengua que debe aprenderse de manera obligatoria;

-en el ámbito educativo debe quedar justificado el dominio de la lengua común, otras lenguas cooficiales pueden figurar pero nunca como lenguas vehiculares exclusivas;

-solo una parte del funcionariado debe estar capacitado para atender al ciudadano en las dos lenguas cooficiales;

-la Administración pública puede tener carácter bilingüe pero nunca hacer uso exclusivo de la lengua cooficial que no sea la lengua común, y

-los representantes políticos deben usar la lengua común salvo en casos especiales o en sus parlamentos autonómicos.

\section{La ambigüedad del marco legal}

Como hemos mencionado anteriormente, la controversia generada en torno al tratamiento por parte de las instituciones públicas hacia las lenguas catalana y castellana está directamente relacionada con la existencia de un marco legal demasiado general a veces (caso de la Constitución de 1978) y claramente ambiguo otras, que justifica y explica en cierto modo la existencia de planteamientos diferentes, a veces radicalmente opuestos.

El Estatuto de Autonomía de Cataluña, en su texto consolidado redactado en febrero de 2013 recoge, tanto en el espacio dedicado a cuestiones lingüísticas en el artículo VI del Título Preliminar como en el Capítulo III, dedicado a los derechos y deberes lingüísticos, el espíritu contradictorio que también recorre la ley de Política lingüística redactada en enero de 1998 por el Parlamento de Cataluña y que representa el auténtico texto legal de carácter general que recoge todos los ámbitos de regulación oficial del uso de la lengua en Cataluña. De manera general, la ambigüedad viene dada en ambos textos por la coexistencia de dos ideas: la cooficialidad de las lenguas catalana y castellana y el carácter de lengua propia del catalán, ya que, como se expresa en el mencionado artículo 6 del Título Preliminar del Estatuto, la cooficialidad obliga a los ciudadanos a conocer ambas lenguas y les otorga el derecho a utilizar las dos (entiéndase cualquiera de las dos, como se recoge en el Estatuto cuando se afirma en el capítulo III que los ciudadanos tienen el derecho de opción lingüística), mientras que la lengua catalana, al ser lengua propia ${ }^{9}$, según el mismo texto «es la lengua de uso normal y preferente de las Administraciones públicas y de los medios de comunicación públicos de Cataluña, y es también la lengua normalmente utilizada como vehicular y de aprendizaje en la enseñanza $»^{10}$ (Parlament de Catalunya 2013: 23). Dicho

\footnotetext{
${ }^{9}$ Una interesante aproximación a las distintas denominaciones y categorizaciones dadas a las lenguas, incluyendo la de lengua propia, desde el punto de vista jurídico, puede encontrarse en Ruiz Vieytez (2004). ${ }^{10}$ Curiosamente, el texto de 2013 recoge en nota al pie que dicha afirmación, clave para entender determinados aspectos de la política lingüística catalana, ha sido calificada como inconstitucional por el Tribunal Constitucional.
} 
marco general puede dar lugar a conflicto ya que puede avalar jurídicamente decisiones difíciles de llevar a la práctica. A modo de ejemplo, un centro de enseñanza puede decidir utilizar el catalán como lengua vehicular (dado su carácter de lengua propia) pero la mayoría de los ciudadanos que asisten al mismo puede decidir usar el castellano como lengua de expresión (dado su carácter de lengua oficial y el derecho de opción lingüística).

Un examen detenido de la Ley de Política lingüística de enero de 1998 refleja la misma sensación, ya que el texto promociona tanto la cooficialidad como la especificidad del catalán y alberga pasajes que pueden resultar en cierto modo contradictorios y legitiman muy diferentes medidas de planificación lingüística en torno a las lenguas implicadas. En las primeras páginas del texto, pertenecientes al preámbulo y el capítulo preliminar, se recoge, por una parte, que la lengua catalana, «elemento fundamental de la formación y la personalidad nacional de Cataluña, (...) instrumento básico de comunicación, integración y cohesión social» (Ley 1/1998, p. 1), es la lengua propia de la comunidad, lo cual «obliga a los poderes públicos y las instituciones de Cataluña a protegerla, a usarla de forma general y a promover su uso público en todos los niveles» (op. cit., p. 2). Sin embargo, por otra parte, se manifiesta el carácter oficial de las lenguas catalana y castellana, se insiste en que ambas lenguas «pueden ser utilizadas indistintamente por los ciudadanos y ciudadanas en todas las actividades públicas y privadas sin discriminación» (op. cit., p. 1) y, en el artículo dedicado a los derechos lingüísticos, se reconoce nuevamente el derecho a expresarse y ser atendido en la lengua que se prefiera.

Más allá de las referencias generales a estas dos ideas, difíciles quizás de conjugar desde nuestro punto de vista, el resto del texto recorre, a través de distintos capítulos, diferentes ámbitos de regulación del uso oficial de la lengua: «El uso institucional», «La onomástica», «La enseñanza», «Los medios de comunicación y las industrias culturales», «La actividad socioeconómica» $\mathrm{y}$ «El impulso institucional». El capítulo I, dedicado al uso institucional, recoge explícitamente la que parece resultar la forma más lógica de armonizar los dos presupuestos de los que venimos hablando, cooficialidad y lengua propia, ya que afirma en un mismo párrafo que las administraciones públicas deben utilizar el catalán pero todo ciudadano tiene derecho a recibir información en castellano solo si lo solicita. En consonancia con dicha idea todo el personal de dichas administraciones debe ser bilingüe y todos los documentos públicos, actuaciones judiciales, procedimientos administrativos, etc., son válidos en ambas lenguas (cf. op. cit., pp. 6-8). Dicho planteamiento, que parte de la promoción del catalán pero sin negar el estatus del castellano, exige un alto nivel de bilingüismo en una parte de la población y puede verse como una medida de fomento de ambas lenguas en la comunidad.

El capítulo III se centra en un aspecto fundamental en la planificación lingüística en situaciones de contacto: la enseñanza. El contenido del mismo vuelve a ser controvertido, ya que se especifica que el catalán es la lengua de la enseñanza en todos los niveles y modalidades educativos, por lo que los centros de enseñanza deben hacer uso del catalán, lengua vehicular de aprendizaje. Pero al mismo tiempo se afirma que los niños tienen derecho a recibir la primera enseñanza en su lengua habitual, sea el catalán o el castellano y que en los centros de enseñanza superior profesorado y alumnado tiene derecho a 
expresarse en la lengua que prefieran. Parece, pues, nuevamente, contraponerse un grupo de directrices dirigido a los centros educativos y otro destinado a los ciudadanos que podría dar lugar, como mencionábamos más arriba, a situaciones de difícil solución. Vuelve a insistirse, eso sí, nuevamente, en la necesidad del carácter bilingüe de parte de la población, en este caso el profesorado (cf. op, cit., p. 9).

En el capítulo IV, dedicado a los medios de comunicación y las industrias culturales, aparecen algunas ideas interesantes. De un lado, vuelve a designarse a la lengua catalana como la normalmente utilizada en los medios de radiodifusión, televisión y comunicación escrita, pero en este caso la presencia de las dos lenguas oficiales se especifica en forma de cuotas, llegándose a afirmar, por ejemplo, como prueba del grado de concreción del texto que comentamos, que en las emisoras de radiodifusión y televisión al menos el veinticinco por ciento de las canciones deben ser interpretadas en lengua catalana o aranesa. De otro lado, en este capítulo aparece una idea, que se repetirá en el capítulo VI dedicado al impulso institucional, como es la necesidad de favorecer, estimular, fomentar y subvencionar la lengua catalana (cf. op, cit., pp. 11-12). Se recoge de esta manera la necesidad de favorecer el impulso de la lengua históricamente minorizada con objeto de paliar esa condición de inferioridad y alcanzar una igualdad en la consideración de prestigio $^{11}$.

El capítulo $\mathrm{V}$, que trata sobre la actividad socioeconómica, el último que comentaremos en este apartado, insiste en esta idea (suerte de discriminación positiva) de promocionar y subvencionar la lengua catalana, ya que recoge que las comunicaciones de las empresas, los rótulos, las comunicaciones megafónicas, la señalización, los carteles o los documentos de ofertas de servicios deben estar, al menos, en catalán y todo ello ha de ser promovido con medidas adecuadas. Eso sí, en un conjunto de artículos entre los que también se afirma que las empresas que desarrollen su actividad en Cataluña deben poder atender a los consumidores en las dos lenguas oficiales, lo que vuelve de nuevo a revelar que el derecho de los ciudadanos puede entrar en cierto conflicto con las políticas lingüísticas empresariales, ya que estos pueden expresarse en lengua castellana si lo desean pero se promociona el uso del catalán en todas las instituciones, por lo que parece abogarse por un modelo bilingüe que podría dar cabida a un monolingüismo en lengua catalana pero nunca en lengua castellana (cf. op. cit., pp. 13-14).

\section{Conclusiones}

La política lingüística en torno a las lenguas catalana y castellana en Cataluña ha experimentado notables diferencias a lo largo del tiempo en función de condicionantes de carácter histórico, social y político. En el siglo XX hemos pasado de un posicionamiento

\footnotetext{
${ }^{11}$ Dicha idea, sostenida por diversos sociolingüistas, es vista, sin embargo, por otros autores, como una amenaza para la lengua no promocionada, que, a pesar de su mayor prestigio histórico, podría verse desplazada en virtud de estas medidas, que no concluirían en una situación de bilingüismo sino en un simple cambio de la lengua minorizada.
} 
oficial a favor de un monolingüismo castellano en lo que respecta al uso público de la lengua durante, por ejemplo, la dictadura franquista, a un aumento considerable de las medidas destinadas al fomento del catalán merced a las acciones del gobierno autonómico desde la llegada de la democracia.

El marco legal que regula el uso público de ambas lenguas (en contextos como la educación, los medios de comunicación o la administración) reconoce tanto el carácter especial del catalán (calificada como lengua propia) como el estado de cooficialidad de las lenguas catalana y castellana. De manera general, en un planteamiento no exento de polémica, parece promoverse de manera clara a la lengua catalana sin dejar de reconocer los derechos lingüísticos de los castellanohablantes, lo que da lugar a enunciados que pueden resultar a veces en cierto modo contradictorios o, al menos, difíciles de conciliar en la práctica.

A nuestro juicio, el futuro de ambas lenguas parece estar inevitablemente ligado al de la política. Una política de marcado carácter centralista disminuiría la defensa del catalán en ámbitos oficiales, lo que provocaría, probablemente, si no la desaparición de dicha lengua, un posible estado de diglosia a favor del castellano, ya existente en diferentes momentos de la historia de Cataluña. Por el contrario, es de suponer que el nacionalismo político catalán continuará acentuando en mayor o menor medida una política lingüística centrada en el fomento de la lengua catalana. Dicho marco de actuación, justificado en varias ocasiones, como decíamos anteriormente, con planteamientos sociolingǘsticos como una medida compensatoria para paliar la ausencia del catalán de la esfera pública durante mucho tiempo con el objetivo de conseguir una igualación entre ambas lenguas como reflejo de bilingüismo, tampoco desembocaría, desde nuestro parecer, en la pérdida del castellano, como algunos prevén, pero sí podría conllevar un diferente nivel de destrezas en ambas lenguas a favor del catalán en lo que respecta básicamente a los registros más formales, especialmente si la presencia del castellano en el ámbito educativo disminuye y su mantenimiento se produce en contextos menos formales y sobre todo de carácter oral.

En el examen de la política lingüística en Cataluña se echa en falta, no obstante, la existencia clara de una tercera alternativa basada en la tradición histórica de ambas lenguas y cuyo objetivo sea el desarrollo de una planificación bilingüe menos ambigua y más clara que persiga verdaderamente un dominio y un nivel de identificación similares en ambas lenguas por parte de la población catalana. Es evidente, como manifiesta Á. López García (2009: 126), que la convivencia plurilingüe no puede imponerse sin un amplio consenso social preexistente, pero no es menos cierto que son los mismos poderes políticos que finalmente son los encargados de desarrollar la planificación lingüística que conduzca a dicho plurilingüismo los capacitados para fomentar esa conciencia en la población. Ni el probable mayor coste económico de un modelo de planificación lingüística bilingüe ni el posible menor rédito político que la defensa de un espíritu identitario híbrido, multilingüe y multicultural reporta deberían ser motivos suficientes para que un pueblo como el catalán renunciara a la enorme riqueza de dos lenguas como catalán y castellano después de tantos siglos. Quizás debamos ser los lingüistas los encargados de reivindicar dicha 
riqueza por encima de planteamientos políticos que solo ven en el lenguaje una enorme herramienta de poder.

Recibido: 12.03 .2014

Aceptado: 14.09.2014

\section{Referencias bibliográficas}

Constitución Española (Boletín Oficial del Estado, número 311, de 29 de diciembre de 1978).

Escoriza Morera, L. (2008): Comentarios de política y planificación lingüísticas. Madrid, Arco/Libros.

Hamel, R. E. (1995): «Derechos lingüísticos como derechos humanos: debates y perspectivas», Alteridades, 5 (10), págs. 11-23.

Herreras, J. C. (2006): Lenguas y normalización en España. Madrid, Gredos.

Ley 1/1998, de 7 de enero, de política lingüística (Diari Oficial de la Generalitat de Catalunya, número 2553, pág. 291, de 9.1.1998).

Ley Orgánica 6/2006, de 19 de julio, de reforma del Estatuto de Autonomía de Cataluña (Boletín Oficial del Estado, número 172, de 20 de julio de 2006), pp. 27.269-27.310.

Lodares, J. R. (2000): El paraíso políglota. Madrid, Taurus.

López García, Á. (2009): La lengua común en la España plurilingüe. Lengua y sociedad en el mundo hispánico, 24. Madrid/Frankfurt, Iberoamericana/Vervuert.

Montero Cartelle, E. (1979): «Castellano o español a la luz de la Constitución. (La historia se repite)», Senara, 1, págs. 231-251.

Moreno Fernández, F. (2005): Principios de sociolingüística y sociología del lenguaje. Barcelona, Ariel.

Parlament de Catalunya (2013): Estatuto de Autonomía de Cataluña. Texto consolidado. Barcelona, Parlament de Catalunya.

Ruíz Vieytez, E. J. (2004): «Lenguas oficiales y lenguas minoritarias: cuestiones sobre su estatuto jurídico a través del derecho comparado», II Simposi Internacional Mercator: Europa 2004: Un nou marc per a totes les llengües?, Tarragona.

Subirats i Humet, J y Gomá, R. (coords.) (1998): Políticas públicas en España: contenidos, redes de actores y niveles de gobierno. Barcelona, Ariel.

Süselbeck, K. (2008): «Lengua, nación e identidad en el discurso de la política lingüística de Cataluña», en Süselbeck, K., Mühlschlegel, U. y Masson, P. (eds.), Lengua, nación e identidad: la regulación del plurilingüismo en España y América latina. Madrid/Frankfurt, Iberoamericana/Vervuert. http://www.gencat.cat/temes/cat/llengua.htm 